\title{
Risk Factors and Spatial Distribution of Schistosoma mansoni Infection among Preschool-Aged Children in Blapleu, Biankouma District, Western Côte d'Ivoire
}

\author{
Constant Konan N'Zi (D), ${ }^{1}$ Mamadou Ouattara, ${ }^{2,3}$ Rufin Kouassi Assarée, ${ }^{2,3,4,5}$ \\ Fidèle Kouakou Bassa, ${ }^{2}$ Nana Rose Diakité, ${ }^{2,3}$ and Eliézer Kouakou N'Goran ${ }^{2,3}$ \\ ${ }^{1}$ Institut National de Santé Publique, Abidjan BP V 46, Côte d'Ivoire \\ ${ }^{2}$ Université Félix Houphouët-Boigny, 22 BP 582, Abidjan 22, Côte d'Ivoire \\ ${ }^{3}$ Centre Suisse de Recherches Scientifiques en Côte D'Ivoire, 01 BP 1303, Abidjan, Côte d'Ivoire \\ ${ }^{4}$ Swiss Tropical and Public Health Institute, CH-4002, Basel, Switzerland \\ ${ }^{5}$ University of Basel, $\mathrm{CH}-4003$, Basel, Switzerland \\ Correspondence should be addressed to Constant Konan N’Zi; konstant_n@yahoo.fr
}

Received 17 May 2021; Accepted 21 September 2021; Published 28 November 2021

Academic Editor: Pedro P. Chieffi

Copyright (c) 2021 Constant Konan N'Zi et al. This is an open access article distributed under the Creative Commons Attribution License, which permits unrestricted use, distribution, and reproduction in any medium, provided the original work is properly cited.

Schistosoma mansoni infection is common among school-age children (SAC) in western Côte d'Ivoire. Little is known on the infection rate of preschool-aged children (PSAC) due to epidemiological data deficiency and nonappropriate formulation of the drug. Thus, mass drug administration for schistosomiasis control mainly targets SAC. This study aims to identify the risk factors and spatial distribution of $S$. mansoni infection among PSAC in Blapleu, endemic foci of $S$. mansoni. We carried out a crosssectional study in households with PSAC aged 1-6 years. A structured questionnaire was administered to mothers/guardians to obtain data on sociodemographics and water contact behaviour of children. Point-of-care circulating cathodic antigen (POCCCA) immunodiagnostic test in urine and Kato-Katz (K-K) method with stool were used for S. mansoni infection diagnosis. Multiple logistic regression analysis was performed to determine the relationship between $S$. mansoni infection and sociodemographic data. Coordinates recorded by a Global Positioning System of households, water source points, and infected PSAC were used to map the spatial distribution of $S$. mansoni infection cases. This study was conducted with 350 PSAC aged 1-6 years. The overall infection prevalence of S. mansoni varies from $31.43 \%$ with the K-K method to $62.86 \%$ with the POC-CCA. PSAC aged 2-6 years were highly infected with $S$. mansoni than those aged 1-2 years (OR $=14.24,95 \%$ CI: 5.85-34.64). PSAC who did not have access and who do not live close to the infected water source were at a significant lower risk of $S$. mansoni infection $(\mathrm{OR}=0.13,95 \%$ CI: 0.057-0.30). The main purpose of water contact of PSAC was to help their mother for laundry that occurs weekly. In Blapleu, a high risk of S. mansoni infection was observed among PSAC. Schistosomiasis control effort in such localities should include information, education, and communication, water, sanitation, and hygiene, and particularly chemotherapy targeting PSAC, reinforcing the need of the paediatric praziquantel formulation.

\section{Introduction}

Schistosomiasis is a neglected tropical disease (NTD) caused by worms (trematodes) of the genus Schistosoma. There are two main forms of schistosomiasis, namely, intestinal schistosomiasis and urogenital schistosomiasis. In 2018, at least 290.8 million people worldwide required preventive treatment for schistosomiasis, and more than 97.2 million people received the treatment [1]. In children, schistosomiasis is associated with chronic anaemia, nutritional impairment, stunted growth, and mental slowness $[2,3]$. Schistosomiasis can lead to cognitive impairment and impacts negatively on children's educational outcomes $[4,5]$. Schistosomiasis is still a major public health challenge in sub-Saharan Africa [6].

In Côte d'Ivoire, western region is a schistosomiasis hyperendemic area with prevalence ranging from $50 \%$ to $100 \%$ in several settings [7-9]. Thus, the country adopted the 


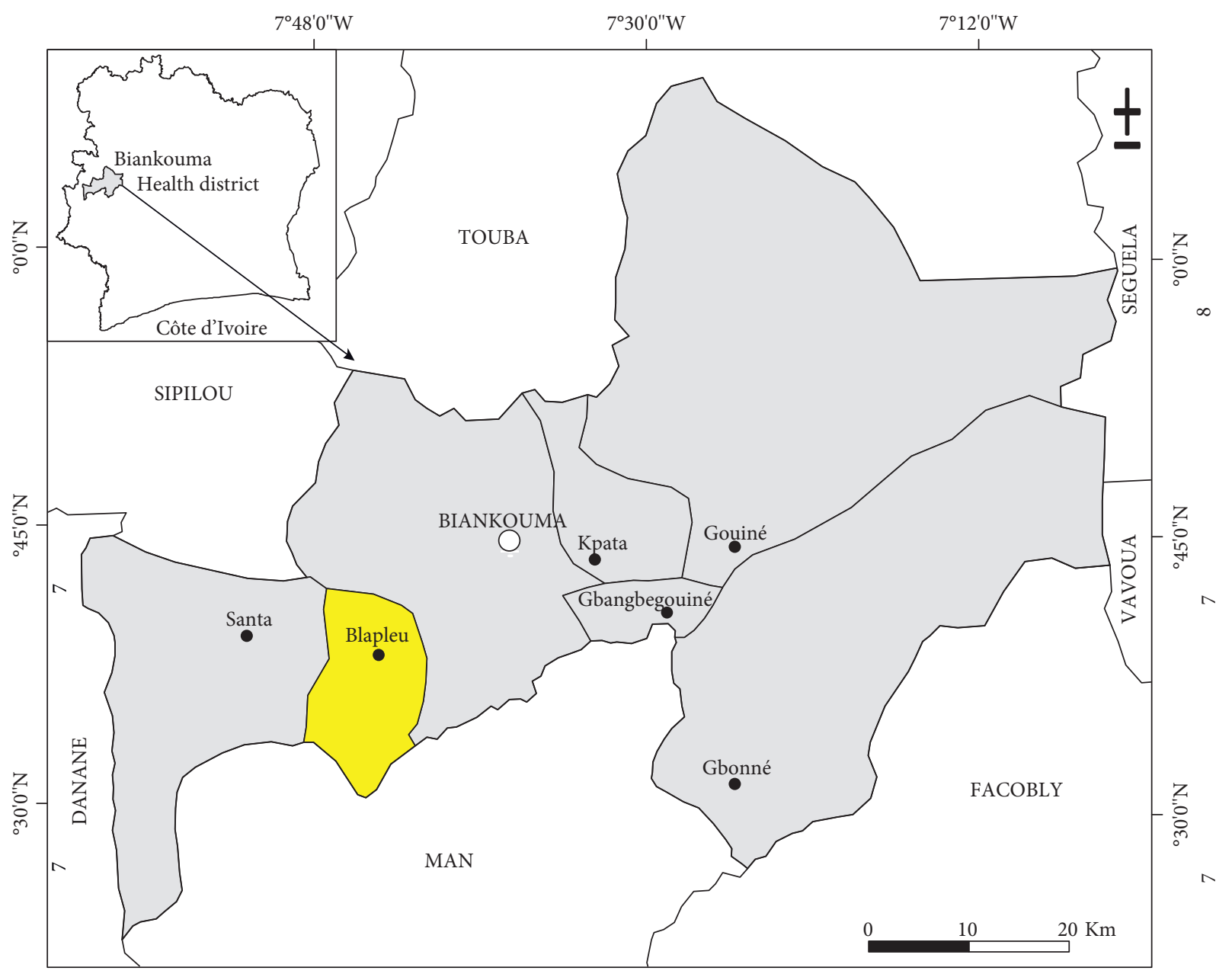

FIGURE 1: Map of western Côte d'Ivoire indicating the study area (in yellow color).

WHO's approach of including mass drug administration (MDA) in NTD control programmes. Accordingly, MDA with praziquantel targeting 6- to 15-year children is implemented since 2011 in endemic areas. This approach fails to include preschool-aged children (PSAC) due to a lack of paediatric praziquantel treatment and epidemiological data [10-13]. Some previous studies have shown in PSAC high prevalence and serious burden on $S$. mansoni infection [14-17]. Therefore, there is a need to include PSAC in preventive chemotherapy for better schistosomiasis control [18-20].

Since 2016, the paediatric praziquantel consortium composed of Japan, Germany, Switzerland, the Netherlands, Brazil, the United Kingdom, Kenya, and Côte d'Ivoire is conducting a clinical trial aimed to find a paediatric praziquantel drug formulation. The first part of this Phase II clinical trial took place in western Côte d'Ivoire. Blapleu city has been particularly affected by schistosomiasis among PSAC aged 2 to 6 years (unpublished data). This study aims to improve our knowledge about the disease transmission, the risk factors, and the spatial distribution of $S$. mansoni infection in PSAC living in Blapleu.

\section{Materials and Methods}

2.1. Ethical Consideration. Ethical clearance was obtained from Comité National d'Ethique et de la Recherche of the Ministry of Public Health and Hygiene of Côte d'Ivoire (reference no. 046/MSHP/CNER-Kp). Written informed consent was systematic for any child's enrolment in the study. The parent/legal guardian could withdraw his child from the study at any time. PSAC infected with S. mansoni were offered free medical checkups and paediatric praziquantel treatment (currently being tested); any other diseases diagnosed on further investigation were managed. Data collected from each child were strictly confidential.

2.2. Study Area. The study was carried out in Blapleu (latitude: $7^{\circ} 37^{\prime} 59.9874^{\prime \prime}$; longitude: $-7^{\circ} 43^{\prime} 59.9874^{\prime \prime}$ ), located in Biankouma health district, Tonkpi region, western Côte d'Ivoire (Figure 1). Tonkpi region is a mountainous area with an average elevation ranging from $300 \mathrm{~m}$ above mean sea level (alms) to slightly above $1000 \mathrm{~m}$ amsl [7]. The climate is subtropical with average temperatures ranging up to $24^{\circ} \mathrm{C}$; the rainy season extends from March to October 
[21]. According to the Institut National de la Statistique de Côte d'Ivoire, there were 14750 inhabitants [22], mostly natives belonging to the "Yacouba" ethnic group. Drinking water is obtained from household wells and pumps. There is a permanent river as well as two primary schools and one health center with trained medical practitioners.

2.3. Study Design, Periods, and Inclusion Criteria. A crosssectional study was conducted from June 2016 to December 2017 for PSAC aged 2-6 years and from July to September 2018 for PSAC aged $1-<2$ years. Children who lived in Blapleu and did not receive any antimalarial or anthelmintic treatment in the last four weeks were eligible.

2.4. Sociodemographic Data Collection. A questionnaire was tested and administered to PSAC parents/legal guardians to collect data on sociodemographics and human-water contact behaviours. First, the households were visited by three chosen community health workers for the identification of PSAC aged 1-2 years. Second, parents/legal guardians with previously identified children were invited to meet the researcher at the Blapleu health center within an agreed time schedule. Children with birth certificate, with written informed consent signed by their parents/legal guardians, and who fulfilled all the aforementioned eligibility criteria were enrolled in the study. Third, the interviewer went to all households in order to administer the questionnaire and to visit with parents'/legal guardian's water point of each selected household. Geographical coordinates were collected by using a GPS (eTrex H, Deutschland, Garmin International, Germany) at the center of each household and at a distance of one meter away from each visited water source.

2.5. Parasitological Survey. A paediatric urinal collector was set up for each PSAC to sample about $10 \mathrm{ml}$ of urine. Urine samples were subjected to point-of-care (POC) circulating cathodic antigen (CCA) test (Schisto POC-CCA cassette-based test, Rapid Medical Diagnostics, Pretoria, South Africa). In brief, two drops of urine were transferred to the well of the cassette. After 20 minutes of absorbance time, the tests were read by an experienced technician. The results were scored as negative or positive (trace results were considered as positive).

Parents of POC-CCA-positive children were given two plastic containers and asked to collect two stool samples of their PSAC at home. The first stool sample was collected, and the second stool sample was provided within sixth days after the first. Stool samples were transferred to the Centre Hospitalier Regional (CHR) de Man and proceeded for S. mansoni eggs' examination according to the Kato-Katz method [23]. Triplicate $47.1 \mathrm{mg}$ Kato-Katz thick smears were prepared per stool sample. After 60 minutes of clearing times, the thick smears were read by three experienced parasitologists. The number of helminth eggs of S. mansoni and soiltransmitted helminth was counted and recorded. Positive results were confirmed if at least two $S$. mansoni eggs were observed from a slide. For quality control, $10 \%$ of the slide were reexamined by one of the senior technicians.
2.6. Data Statistical Analysis. Data analysis was performed using STATA (version IC13.1; Stata Corporation, College Station, TX). The relationship between $S$. mansoni infection and the potential risk factors was evaluated by a multivariate logistic regression model. ArcMap (version 10.5.1, Environmental Systems Research Institute Inc.; Redlands, California, United States of America) was used to determine distances between households and the water source points. ArcView (version 3.2, Redlands, USA) was used to generate the map of households, water source points, and spatial distribution of $S$. mansoni infection cases.

\section{Results}

3.1. Sociodemographic Characteristics of Study Participants. Overall, 350 PSAC including 193 males (55.14\%) and 157 females $(44.86 \%)$ participated in the study (Table 1$)$. There were less children aged 1-<2 years, 105 (30\%), than the ones aged 2-6 years, 245 (70\%). Most of the children mainly lived in traditional households (90.29\%) with 1 to 3 rooms (74.57\%) and 3 to 6 inhabitants $(67.15 \%)$. Latrine availability was limited (19.86\%), and household water was provided mainly from traditional boreholes $(83.75 \%)$. Inhabitants of over half of the households were foreigners (56\%). Islam was the religion most practiced (43.43\%), and most of the mothers were illiterate (76.57\%).

3.2. Prevalence of S. mansoni Infection Based on the POC-CCA and $\mathrm{K}-\mathrm{K}$ Methods. Based on the POC-CCA method, $62.86 \%$ (220/350) children were infected with S. mansoni. There was no difference in the $S$. mansoni prevalence in PSAC between male and female and age groups (Table 2).

Using K-K, the overall S. mansoni prevalence was $31.43 \%$ $(110 / 350)$. The $S$. mansoni prevalence infection was significantly higher in children aged $2-6$ years $(40.41 \%, 95 \%$ CI: $57.47-72.79 \%$ ) compared with those aged $1-<2$ years (10.48\%, 95\% CI: 7.20-25.15\%), and there was no significant gender difference (Table 2).

3.3. Frequency of Water Source Point Visits. Nearly half of PSAC (49.14\%) were regularly visiting a water source point together with their mothers/legal guardians (89.39\%). Mothers/legal guardians were visiting water source points at least weekly (78.95\%) and washing clothes accounted with $83.83 \%$. Most PSAC (86.24\%) were exposed to water source points through swimming and laundry, but $25 \%$ of PSAC, namely, those aged $1-<2$ years $(n=13)$, were carried on their mother's backs with no visible water contact. About $20 \%$ of PSAC aged 2-6 years go alone to water source points for recreation activities (Table 3 ).

3.4. Risk Factors Associated with S. mansoni Infection in PSAC. Multivariate logistic regression analysis on sociodemographic data, water contact pattern, and distance from the household to water source points has identified two main risk factors. Children aged 2-6 years had significantly higher odds of $S$. mansoni infection compared to $1-<2$-year 
TABle 1: Sociodemographic characteristics of 1-6-year children in Blapleu, Biankouma District, Western Côte d'Ivoire.

\begin{tabular}{|c|c|c|c|}
\hline Characteristics & $1-<2$ years, $n(\%)$ & $2-6$ years, $n(\%)$ & Added values, $n(\%)$ \\
\hline \multicolumn{4}{|l|}{$\operatorname{Sex}$} \\
\hline Male & $63(60.00)$ & $130(53.06)$ & $193(55.14)$ \\
\hline Female & $42(40.00)$ & $115(46.94)$ & $157(44.86)$ \\
\hline \multicolumn{4}{|l|}{ Mother's education } \\
\hline Unschooled & $84(80.00)$ & $184(75.08)$ & $268(76.57)$ \\
\hline Primary school & $18(17.14)$ & $39(15.93)$ & $57(16.29)$ \\
\hline College & $03(02.86)$ & $22(08.99)$ & $25(07.14)$ \\
\hline \multicolumn{4}{|l|}{ Household type } \\
\hline Traditional & $91(86.67)$ & $226(92.25)$ & $317(90.29)$ \\
\hline Modern & $14(13.33)$ & $19(07.75)$ & $33(09.71)$ \\
\hline \multicolumn{4}{|l|}{ Household size } \\
\hline$[3-6]$ & $60(57.14)$ & $175(71.43)$ & $235(67.15)$ \\
\hline [7-8] & $25(23.81)$ & $38(15.51)$ & $63(18.00)$ \\
\hline$[9-10]$ & $12(01.43)$ & $23(09,39)$ & $35(10.00)$ \\
\hline [11-12] & $08(07.62)$ & $09(03.67)$ & $17(04.85)$ \\
\hline \multicolumn{4}{|c|}{ Household number rooms } \\
\hline$[1-3]$ & $70(66.67)$ & $191(77.96)$ & $261(74.57)$ \\
\hline$[4-7]$ & $35(33.33)$ & $54(22.04)$ & $89(25.43)$ \\
\hline \multicolumn{4}{|c|}{ Children defecation site } \\
\hline Latrine & $04(03.81)$ & $88(35.92)$ & $92(19.86)$ \\
\hline Open air & $31(29.52)$ & $95(38.78)$ & $126(34.15)$ \\
\hline Basin/container & $70(66.67)$ & $62(25.30)$ & $132(45.99)$ \\
\hline \multicolumn{4}{|l|}{ Household water } \\
\hline Domestic boring & $100(95.25)$ & $177(72.26)$ & $277(83,75)$ \\
\hline Paid water pump & $02(01.90)$ & $23(09,39)$ & $25(05.65)$ \\
\hline Free water pump & $01(00.95)$ & $14(05,70)$ & $15(03.33)$ \\
\hline Backmatter & $02(01.90)$ & $31(12.65)$ & $33(07.27)$ \\
\hline \multicolumn{4}{|l|}{ Ethnic group } \\
\hline Aboriginal & $34(32.38)$ & $121(49.39)$ & $154(44.00)$ \\
\hline Allochtone & $71(67.62)$ & $125(50.61)$ & $196(56.00)$ \\
\hline \multicolumn{4}{|l|}{ Religion } \\
\hline Christian & $18(17.14)$ & $65(26.52)$ & $83(23.71)$ \\
\hline Muslim & $57(54.29)$ & $95(38.78)$ & $152(43.43)$ \\
\hline Buddhist & $00(00.00)$ & $02(00.82)$ & $02(00.57)$ \\
\hline No religion & $30(28.57)$ & $83(33.88)$ & $113(32.29)$ \\
\hline
\end{tabular}

TABle 2: Prevalences of S. mansoni infection according to the diagnostic test, the age, and the gender in 350 PSAC in Blapleu, Biankouma District, Western Côte d'Ivoire.

\begin{tabular}{|c|c|c|c|c|c|}
\hline & & $N$ examined & $n$ infected (\%) prevalence & 95\% confidence interval & $P$ value \\
\hline POC-CCA & & 350 & $220(62.86)$ & & \multirow{3}{*}{0.77} \\
\hline \multirow{2}{*}{ Gender } & Male & 193 & $120(62.18)$ & $55.27-69.08$ & \\
\hline & Female & 157 & $100(63.69)$ & $56.09-71.30$ & \\
\hline \multirow{2}{*}{ Age group } & $1-<2$ years & 105 & $68(64.76)$ & $55.47-74.05$ & \multirow{2}{*}{0.63} \\
\hline & $2-6$ years & 245 & $152(62.04)$ & $55.92-68.16$ & \\
\hline Kato-Katz & & 220 & $110(31.43)$ & & \multirow{3}{*}{0.42} \\
\hline \multirow{2}{*}{ Gender } & Male & 120 & $63(32.64)$ & $43.43-61.56$ & \\
\hline & Female & 100 & $47(29.94)$ & $37.05-56.95$ & \\
\hline \multirow{2}{*}{ Age group } & $1-<2$ years & 68 & $11(10.48)$ & $7.2-25.15$ & \multirow{2}{*}{$<0.001$} \\
\hline & $2-6$ years & 152 & $99(40.41)$ & $57.47-72.79$ & \\
\hline
\end{tabular}

children $(\mathrm{OR}=14.24,95 \% \mathrm{CI}$ : 5.85-34.64), while children not exposed to the water point had lower odds of S. mansoni infection $(\mathrm{OR}=0.13,95 \% \mathrm{CI}: 0.057-0.30)$. Spatial distribution was homogeneous in $S$. mansoni infection using POC-CCA (Figure 2(a)). In contrast, K-K method showed that $S$. mansoni infections were distributed in a concentric pattern close to water source points (Figure 2(b)).

\section{Discussion}

This study provides knowledge and information on S. mansoni infection epidemiology of PSAC living in a highly endemic locality in western Côte d'Ivoire. The prevalence of S. mansoni infection, risk factors, and spatial distribution in this area were identified. The overall S. mansoni prevalence 
TABLe 3: Use of water contact points by the 350 PSAC and their mothers in Blapleu, Biankouma District, Western Côte d'Ivoire.

\begin{tabular}{|c|c|c|c|}
\hline Characteristics & $1-<2$ years, $n(\%)$ & $2-6$ years, $n(\%)$ & Added values, $n(\%)$ \\
\hline \multicolumn{4}{|l|}{ Go to the water contact point } \\
\hline Yes & $53(50.48)$ & $119(48.57)$ & $172(49.14)$ \\
\hline No & $52(49.52)$ & $126(51.43)$ & $178(50.86)$ \\
\hline \multicolumn{4}{|c|}{ Purpose for visiting the water contact point } \\
\hline Helping mother with housework & $52(98.11)$ & $96(80.67)$ & $148(89.39)$ \\
\hline Friendly bathing & $1(01.89)$ & $23(19.33)$ & $24(10.61)$ \\
\hline \multicolumn{4}{|l|}{ Children's activities on water points } \\
\hline Laundry/bathing & $39(75)$ & $116(97.48)$ & $155(86.24)$ \\
\hline Carried on mother's back & $13(25)$ & $3(02.52)$ & $16(13.76)$ \\
\hline \multicolumn{4}{|l|}{ Mother's activities at the water point } \\
\hline Laundry & $49(92.45)$ & $88(75.21)$ & $97(83.33)$ \\
\hline Supplying water & $4(07.55)$ & $26(22.23)$ & $30(14.89)$ \\
\hline Rice fields & 0 & $5(02.56)$ & $5(01.28)$ \\
\hline \multicolumn{4}{|c|}{ Mother and water point contact frequency } \\
\hline Daily & $04(07.55)$ & $9(07.56)$ & $13(07.00)$ \\
\hline Weekly & $38(71.70)$ & $99(83.20)$ & $137(78.00)$ \\
\hline Twice a week & $11(20.75)$ & $11(09.24)$ & $22(15.00)$ \\
\hline
\end{tabular}

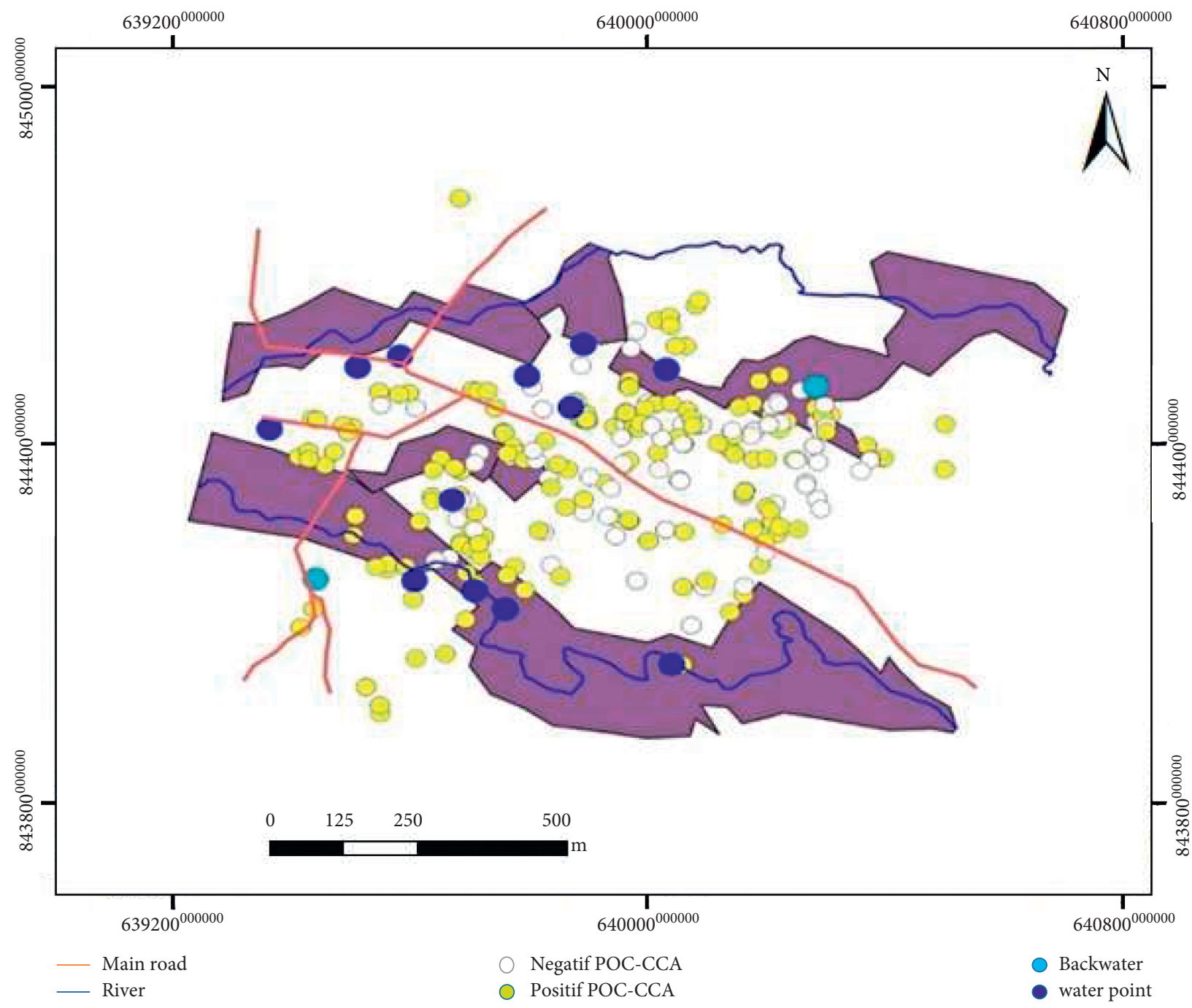

(a)

Figure 2: Continued. 


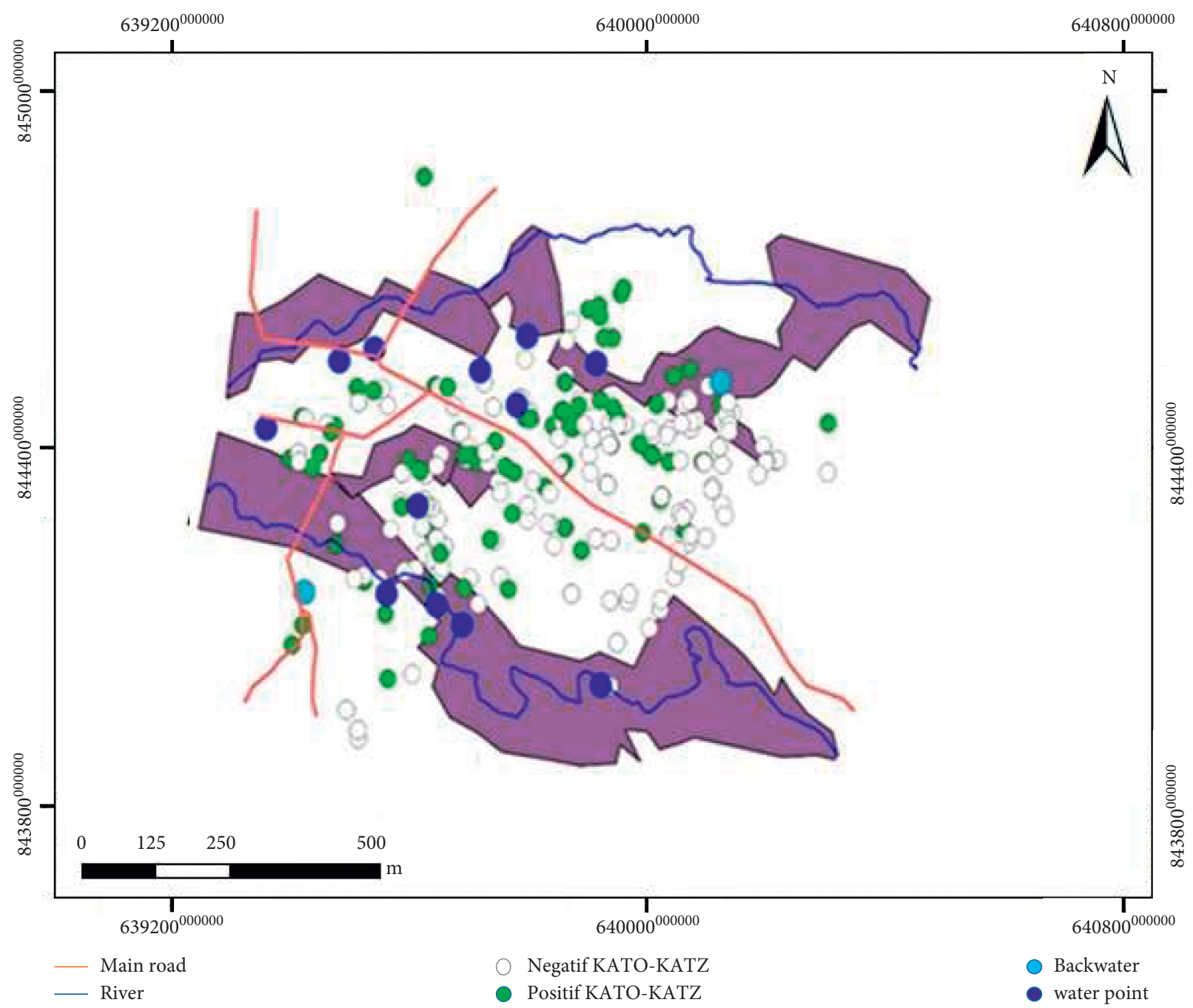

(b)

Figure 2: Schistosoma mansoni infections based on POC-CCA (a) and K-K (b) methods among PSAC in Blapleu, Western Côte d'Ivoire.

among PSAC observed from this study was very high compared to the reported data in Côte d'Ivoire [16]. Indeed, the western region is still considered to be a major endemic area for S. mansoni in Côte d'Ivoire [7, 8].

The prevalence of $S$. mansoni infection using the POCCCA test was two times higher than the K-K method $(62.86 \%$ versus $31.43 \%)$. Previous studies carried out in western Côte d'Ivoire [24] and other countries also confirm this result $[17,25,26]$. In addition, POC-CCA tests were reported to be 3 to 9 times more sensitive than the $\mathrm{K}-\mathrm{K}$ method [27, 28]. POC-CCA sensitivity and specificity ranged from 76.7 to $99.1 \%$ and $75 \%$, respectively [15, 29]. However, POC-CCA test findings are speculative due to the detection of antibodies to $S$. mansoni which could either confirm the diagnosis of the disease or reflect an old infection [30]. In contrast, results with the K-K technique are approximate when $S$. mansoni eggs are in small number in the stool sample. As well as in previous studies [15, 24], we noted that there was no association between the prevalence of S. mansoni infection and gender. One reason of this finding might be frequency of the visits at the water source that was identical for all PSAC.

Based on the K-K method, S. mansoni infection prevalence was significantly higher in PSAC aged 2-6 years. Similar findings from Tanzania [15] also demonstrated that schistosomiasis prevalence increased as PSAC get older. Indeed, children belonging to this age group were most active and autonomous with regard to their parents. However, in Ethiopia [31], a nonstatistically significant relationship was reported. A plausible explanation might be the behaviour of children of this age category.

Using POC-CCA, the overall prevalence for S. mansoni infection was $62.86 \%$ within $1-<2$ years $(64.76 \%)$ versus $62.04 \%$ in $2-6$ years. This finding brings up an issue concerning S. mansoni infection diagnosed with POC-CCA testing in lactating infants. Presumably, POC-CCA testing in PSAC aged $1-<2$ was able to screen antibodies coming from the mother through breastfeeding $[32,33]$.

In Blapleu, there were two mean risk factors associated with $S$. mansoni infection, namely, children aged 2-6 years 
and exposure to water source points. Household tasks such as laundry were mainly carried out on various water sources within the community.

The mothers/legal guardians typically visited these water sources together with family children, including PSAC aged 2 to 6 years in order to help them with laundry. Children took this opportunity for bathing in the water source. A recent study reported similar findings except that mothers were the only ones involved in doing the laundry [34]. Several studies revealed other schistosomiasis risk factors such as fishing and swimming as activities practiced by PSAC in an analogous setting $[17,35]$.

\section{Conclusion}

This study revealed a high prevalence of $S$. mansoni infection among PSAC in Blapleu community by using the POC-CAC diagnostic method and moderate based on the K-K technique. This study also showed that 2-6-year-old PSAC who had frequent contact with water sources in this locality had a higher risk of $S$. mansoni infection. In addition, reported cases of $S$. mansoni infection were mainly distributed in a concentric pattern close to the water source. Schistosomiasis control effort in such localities should include information, education, and communication (IEC) and water, sanitation, and hygiene (WASH). In particular, it appears crucial that mass drug administration (MDA) for the control of schistosomiasis also takes into account the PSAC in this area. This explains the interest in strengthening research for a paediatric praziquantel formulation.

\section{Data Availability}

The data used to support the findings of this study are available from the corresponding author upon request.

\section{Conflicts of Interest}

The authors declare no conflicts of interest regarding the published article.

\section{Authors' Contributions}

O. Mamadou and C. K. N'Zi designed the study. O. Mamadou, C. K. N'Zi, F. K. Bass, and N. R. Diakité conducted fields investigations. R. K. Assaré, C. K. N'Zi, and O. Mamadou performed analysis and data interpretation and wrote this paper. E. K. N'Goran supervised all processes. All authors read and approved the final manuscript.

\section{Acknowledgments}

The authors are grateful to the secretary of Pediatric Praziquantel Consortium for their support. They thank all staff involved in the project for their support in the field and laboratory. They would also like to acknowledge and thank administrative staff, village authorities, health center staff, and the entire population of Blapleu for their involvement in this project. They thank the team of Laboratoire Biologie et Santé of Université Félix Houphouët-Boigny, Côte d'Ivoire.

\section{References}

[1] WHO, Schistosomiasis, World Health Organization, Geneva, Switzerland, 2020, https://www.who.int/news-room/factsheets/detail/schistosomiasis.

[2] L. A. T. Tchuenté, A. Rodriguez- Morales, "control of schistosomiasis and soil transmitted helminthiasis in subsaharan africa: challenges and prospects," Current Topics in Tropical Medicine, pp. 359-376, Centre for Schistosomiasis and Parasitology, Yaoundé, Cameron, 2012.

[3] A. G. Ross, D. P. McManus, J. Farrar, R. J. Hunstman, D. J. Gray, and Y.-S. Li, "Neuroschistosomiasis," Journal of Neurology, vol. 259, no. 1, pp. 22-32, 2012.

[4] A. D. Sircar, P. N. M. Mwinzi, I. O. Onkanga, R. E. Wiegand, S. P. Montgomery, and W. E. Secor, "Schistosoma mansoni mass drug administration regimens and their effect on morbidity among schoolchildren over a 5-year period-Kenya, 2010-2015," The American Journal of Tropical Medicine and Hygiene, vol. 99, no. 2, pp. 362-369, 2018.

[5] C. H. King and M. Dangerfield-Cha, "The unacknowledged impact of chronic schistosomiasis," Chronic Illness, vol. 4, no. 1, pp. 65-79, 2008.

[6] WHO, Female Genital Schistosomiasis: A Pocket Atlas for Clinical Health-Care Professionals, World Health Organization, Geneva, Switzerland, 2017, https://apps.who.int/iris/ handle/10665/180863.

[7] R. K. Assaré, Y. S. Lai, and Y. N. Tian-Bi, “The spatial distribution of Schistosoma mansoni infection in four regions of western Côte d'Ivoire," Geospatial Health, vol. 10, no. 1, p. 345, 2015.

[8] R. K. Assaré, S. Knopp, and N. A. N’Guessan, "Sustaining control of Schistosomiasis mansoni in moderate endemicity areas in western Côte d'Ivoire: a SCORE study protocol," BMC Public Health, vol. 14, p. 1290, 2014.

[9] WHO, C. . d'Ivoire: Maladies Transmissibles Profil Épidémiologique, World Health Organization, Geneva, Switzerland, 2010, https://apps.who.int/iris/handle/10665/ 70655 .

[10] J. T. Coulibaly, Y. K. N'gbesso, S. Knopp, J Keiser, E. K N'Goran, and J Utzinger, "Efficacy and safety of praziquantel in preschool-aged children in an area co-endemic for Schistosoma mansoni and S. haematobium," PLoS Neglected Tropical Diseases, vol. 6, p. e1917, 2012.

[11] J. R. Stothard, J. C. Sousa-Figueiredo, M. Betson et al., "Closing the praziquantel treatment gap: new steps in epidemiological monitoring and control of schistosomiasis in African infants and preschool-aged children," Parasitology, vol. 138, no. 12, pp. 1593-1606, 2011.

[12] J. Keiser, K. Ingram, and J. Utzinger, “Antiparasitic drugs for paediatrics: systematic review, formulations, pharmacokinetics, safety, efficacy and implications for control," Parasitology, vol. 138, no. 12, pp. 1620-1632, 2011.

[13] A. Dabo, H. M. Badawi, B. Bary, and O. K. Doumbo, "Urinary schistosomiasis among preschool-aged children in Sahelian rural communities in Mali," Parasites \& Vectors, vol. 4, no. 1, p. 21, 2011.

[14] S. Ndokeji, H. D. Mazigo, and M. Temu, "Prevalence and intensity of Schistosoma mansoni and hookworm infections among pre-school and school-aged children in Ilemela District, northwestern Tanzania," Tanzania Journal of Health Research, vol. 18, no. 2, 2016.

[15] D. M. Ruganuza, H. D. Mazigo, R. Waihenya, D. Morona, and G. M. Mkoji, "Schistosoma mansoni among pre-school children in Musozi village, Ukerewe Island, North-Western-Tanzania: 
prevalence and associated risk factors," Parasites \& Vectors, vol. 8, p. 377, 2015.

[16] J. T. Coulibaly, Y. K. N'Gbesso, and N. A. N'Guessan, “Epidemiology of schistosomiasis in two high-risk communities of south Côte d'Ivoire with particular emphasis on preschool-aged children," The American Journal of Tropical Medicine and Hygiene, vol. 89, no. 1, pp. 32-41, 2013.

[17] M. H. Hodges, J. Paye, M. M. Koroma, E. D. Nyorkor, I. Fofonah, and Y. Zhang, "High level of Schistosoma mansoni infection in pre-school children in Sierra Leone highlights the need in targeting this age group for praziquantel treatment," Acta Tropica, vol. 124, no. 2, pp. 120-125, 2012.

[18] J. T. Coulibaly, G. Panic, K. D. Silué, J Kovač, J Hattendorf, and J. Keiser, "Efficacy and safety of praziquantel in preschool-aged and school-aged children infected with Schistosoma mansoni: a randomised controlled, parallel-group, dose-ranging, phase 2 Trial," The Lancet. Global health, vol. 5, no. 7, pp. e688-698, 2017.

[19] N. Kittur, J. D. Castleman, C. H. Campbell, C. H. King, and D. G. Colley, "Comparison of Schistosoma mansoni prevalence and intensity of infection, as determined by the circulating cathodic antigen urine assay or by the Kato-Katz fecal assay: a systematic Review," The American Journal of Tropical Medicine and Hygiene, vol. 94, no. 3, pp. 605-610, 2016.

[20] J. R. Stothard, J. C. Sousa-Figueiredo, M. Betson, A. Bustinduy, and J. Reinhard-Rupp, "Schistosomiasis in African infants and preschool children: let them now be treated!" Trends in Parasitology, vol. 29, no. 4, pp. 197-205, 2013.

[21] B. C. Tiesse, E. N. Wandan, and D. H. N'da, “Apport de La télédétection Pour le suivi spatiotemporel de l'occupation du sol dans la region montagneuse du Tonkpi (Côte d'Ivoire)," European Scientific Journal, vol. 13, no. 15, 2017.

[22] INS, "Recensement Général de la Population et de l'Habitat (RGPH)," Institut National de la Statistique, Côte d'Ivoire, Répertoire des localités: région du Tonkpi, 2014.

[23] N. Katz, A. Chaves, and J. Pellegrino, "A simple device for quantitative stool thick smears technique in Schistosomiasis mansoni," Journal of the São Paulo Institute of Tropical Medicine, vol. 14, no. 6, pp. 397-400, 1972.

[24] R. K. Assaré, M. Tra BI, and M. Ouattara, "Sensitivity of the point-of-care circulating cathodic antigen urine cassette test for diagnosis of Schistosoma mansoni in low-endemicity settings in Cote d'Ivoire," The American Journal of Tropical Medicine and Hygiene, vol. 99, no. 6, pp. 1567-1572, 2018.

[25] A. M. D. Navaratnam, M. J. Mutumba-Nakalembe, J. R. Stothard, N. B. Kabatereine, A. Fenwick, and J. C. SousaFigueiredo, "Notes on the use of urine-CCA dipsticks for detection of intestinal schistosomiasis in preschool children," Transactions of the Royal Society of Tropical Medicine and Hygiene, vol. 106, no. 10, pp. 619-622, 2012.

[26] C. J. Standley, N. J. Lwambo, C. N. Lange, H. C Kariuki, M Adriko, and J. R Stothard, "Performance of circulating cathodic antigen (CCA) urine-dipsticks for rapid detection of intestinal schistosomiasis in schoolchildren from shoreline communities of Lake Victoria," Parasites \& Vectors, vol. 3, no. 7, p. 7, 2010.

[27] D. G. Colley, S. Binder, C. Campbell et al., "A five-country evaluation of a point-of-care circulating cathodic antigen urine assay for the prevalence of schistosoma mansoni," The American Journal of Tropical Medicine and Hygiene, vol. 88, no. 3, pp. 426-432, 2013.

[28] J. Utzinger, M. Booth, E. K. Müller, M. Tanner, and C. Lengeler, "Relative contribution of day-to-day and intra- specimen variation in faecal egg counts ofSchistosoma mansonibefore and after treatment with praziquantel," Parasitology, vol. 122, no. 5, pp. 537-544, 2001.

[29] J. T. Coulibaly, S. Knopp, and N. A. N'Guessan, “Accuracy of urine circulating cathodic antigen (CCA) test for Schistosoma mansoni diagnosis in different settings of Côte d'Ivoire," PLoS Neglected Tropical Diseases, vol. 5, no. 11, 2011.

[30] R. F. Q. Grenfell, D. Taboada, L. A. Coutinho et al., "Innovative methodology for point-of-care circulating cathodic antigen with rapid urine concentration for use in the field for detecting low Schistosoma mansoni infection and for control of cure with high accuracy," Transactions of the Royal Society of Tropical Medicine and Hygiene, vol. 112, no. 1, pp. 1-7, 2018.

[31] A. Alemu, Y. Tegegne, D. Damte, and M. Melku, "Schistosoma mansoni and soil-transmitted helminths among preschoolaged children in Chuahit, Dembia district, northwest Ethiopia: prevalence, intensity of infection and associated risk factors," BMC Public Health, vol. 16, p. 422, 2016.

[32] N. Dauby, T. Goetghebuer, T. R. Kollmann, J. Levy, and A. Marchant, "Uninfected but not unaffected: chronic maternal infections during pregnancy, fetal immunity, and susceptibility to postnatal infections," The Lancet Infectious Diseases, vol. 12, no. 4, pp. 330-340, 2012.

[33] S. E. Odogwu, N. K. Ramamurthy, N. B. Kabatereine et al., "Schistosoma mansoniin infants (aged," Annals of Tropical Medicine and Parasitology, vol. 100, no. 4, pp. 315-326, 2006.

[34] M. J. Mutsaka-Makuvaza, Z. Matsena-Zingoni, A. Katsidzira et al., "Urogenital schistosomiasis and risk factors of infection in mothers and preschool children in an endemic district in Zimbabwe," Parasites \& Vectors, vol. 12, no. 1, p. 427, 2019.

[35] R. K. M’Bra, B. Koné, and Y. G. Yapi, "Risk factors for schistosomiasis in an urban area in northern Côte d'Ivoire," Infectious diseases of poverty, vol. 7, p. 377, 2018. 